\title{
Heating Performance of a Solar Chimney Combined PCM: A Numerical Case Study
}

\author{
Shuli Liü, ${ }^{\mathrm{a}, \mathrm{b}}$, Yongcai Li ${ }^{\mathrm{c}, *}$ \\ a Key Laboratory of New Technology for Construction of Cities in Mountain Area, Chongqing University, China \\ b Department of the Civil Engineering, Architecture and Buildings, Faculty of Engineering and computing, \\ Coventry University, CV1 5FB, UK \\ ${ }^{\mathrm{c}}$ Faculty of the Urban Construction \& Environment Engineering, Chongqing University, China \\ *Corresponding author: Dr. Yongcai Li \\ Contact address: Faculty of the Urban Construction \& Environment Engineering, Chongqing University, 400030, China \\ Email: yongcail@yahoo.com, Tel: +86(0)23 65123777
}

\section{ABSTRACT}

An experimentally validated numerical model is developed to study the effects of seven design and operational parameters on the heating performance of a solar chimney incorporated with phase change material (PCM) in this paper. It is found that when the latent heat increases from 70 to $170 \mathrm{~kJ} / \mathrm{kg}$, the melting time is increased by $103 \%$ and freezing time is prolonged by $60 \%$. If heat flux is increased by $33 \%$, the melting time is reduced by $36.4 \%$. Increasing thermal conductivity of the insulation material from 0.02 to $0.06 \mathrm{~W} / \mathrm{m} \mathrm{K}$, the melting time is prolonged by $47.2 \%$. When absorptivity of the absorber is increased from 0.8 to 1.0 , the melting time is decreased by $26.3 \%$. When transmissivity of the glass cover is increased by $25 \%$, the melting time is reduced by $26.7 \%$. For the inlet air temperature, when it decreases from 25 to $15^{\circ} \mathrm{C}$, the freezing time is shortened by $39 \%$. The melting time is only reduced by $8 \%$ when thermal conductivity of the absorber is increased by 25 times. Therefore, it can be concluded that the first six parameters have more impact on the system's performance. While the thermal conductivity of absorber slightly impacts it.

Keywords: Solar chimney; Phase change material; Heating performance; Numerical study

\begin{tabular}{|ll|}
\hline NOMENCLATURE \\
$A_{w}$ & area of absorber plate, $\mathrm{m}^{2}$ \\
$A_{g}$ & area of glass cover, $\mathrm{m}^{2}$ \\
\hline
\end{tabular}




\begin{tabular}{|c|c|}
\hline$A_{i}$ & chimney inlet area, $\mathrm{m}^{2}$ \\
\hline$A_{o}$ & chimney outlet area, $\mathrm{m}^{2}$ \\
\hline$A_{r}$ & aspect ratio \\
\hline$C$ & sensible heat of the PCM, kJ/kg K \\
\hline$C_{g}$ & specific heat of glass cover, $\mathrm{kJ} / \mathrm{kg} \mathrm{K}$ \\
\hline$C_{d}$ & discharge coefficient \\
\hline$C_{e f f}$ & effective heat capacity of the PCM, $\mathrm{kJ} / \mathrm{kg} \mathrm{K}$ \\
\hline$C_{f}$ & specific heat of fin, $\mathrm{kJ} / \mathrm{kg} \mathrm{K}$ \\
\hline$C_{p . l}$ & specific heat of liquid $\mathrm{PCM}, \mathrm{kJ} / \mathrm{kg} \mathrm{K}$ \\
\hline$C_{p, s}$ & specific heat of solid PCM, kJ/kg K \\
\hline$C_{w}$ & specific heat of absorber plate, $\mathrm{kJ} / \mathrm{kg} \mathrm{K}$ \\
\hline$g$ & gravitational acceleration, $\mathrm{m} / \mathrm{s}^{2}$ \\
\hline$h$ & latent heat of fusion, $\mathrm{kJ} / \mathrm{kg}$ \\
\hline$L$ & height along the chimney, $\mathrm{m}$ \\
\hline$k$ & thermal conductivity, W/m K \\
\hline$k_{a}$ & thermal conductivity of air, $\mathrm{W} / \mathrm{m} \mathrm{K}$ \\
\hline$k_{e f f}$ & effective thermal conductivity of PCM/fin, W/m K \\
\hline$k_{f}$ & thermal conductivity of fin, W/m K \\
\hline$k_{\text {ins }}$ & thermal conductivity of insulation material, W/m K \\
\hline$k_{p}$ & thermal conductivity of PCM, W/m K \\
\hline$m$ & air airflow rate, $\mathrm{kg} / \mathrm{s}$ \\
\hline$q_{s}$ & applied heat flux, $\mathrm{W} / \mathrm{m}^{2}$ \\
\hline$h_{r, w-g}$ & radiative heat transfer coefficient between absorber and glass cover $\left(\mathrm{W} / \mathrm{m}^{2} \mathrm{~K}\right)$ \\
\hline$h_{c v, g-a}$ & convective heat transfer coefficient between glass cover and air in channel $\left(\mathrm{W} / \mathrm{m}^{2} \mathrm{~K}\right)$ \\
\hline$h_{c v, w-a}$ & convective heat transfer coefficient between absorber and air in channel $\left(\mathrm{W} / \mathrm{m}^{2} \mathrm{~K}\right)$ \\
\hline$h_{w-p}$ & overall heat transfer coefficient from the absorber plate to the PCM, $\left(\mathrm{W} / \mathrm{m}^{2} \mathrm{~K}\right)$ \\
\hline$h_{\text {wind }}$ & convective heat transfer coefficient due to wind over glass cover $\left(\mathrm{W} / \mathrm{m}^{2} \mathrm{~K}\right)$ \\
\hline$t$ & time, $\mathrm{s}$ \\
\hline$T$ & temperature, $\mathrm{K}$ \\
\hline$T_{1}$ & the lower limit of the melting temperature range, $\mathrm{K}$ \\
\hline$T_{2}$ & the higher limit of the melting temperature range, $\mathrm{K}$ \\
\hline$T_{\text {air }}$ & mean air temperature inside cavity, $\mathrm{K}$ \\
\hline$T_{a}$ & trapped air temperature, $\mathrm{K}$ \\
\hline$T_{a m b}$ & ambient temperature, $\mathrm{K}$ \\
\hline$T_{g}$ & temperature of glass cover, $\mathrm{K}$ \\
\hline$T_{i}$ & air inlet temperature, $\mathrm{K}$ \\
\hline$T_{o}$ & air outlet temperature, $\mathrm{K}$ \\
\hline$T_{p, i}$ & PCM temperature for internal node $\mathrm{i}, \mathrm{K}$ \\
\hline$T_{p}$ & temperature of PCM, K \\
\hline$T_{w}$ & temperature of absorber plate, $\mathrm{K}$ \\
\hline$T_{\text {sky }}$ & sky temperature $(\mathrm{K})$ \\
\hline$U_{t}$ & overall heat transfer coefficient from glass cover to ambient, $\left(\mathrm{W} / \mathrm{m}^{2} \mathrm{~K}\right)$ \\
\hline$U_{\text {ins }}$ & overall heat transfer coefficient between PCM and ambient through insulation material, \\
\hline$V$ & volume of PCM container, $\mathrm{m}^{3}$ \\
\hline$V_{f}$ & volume of fin, $\mathrm{m}^{3}$ \\
\hline$V_{p}$ & volume of PCM, $\mathrm{m}^{3}$ \\
\hline$V_{\text {wind }}$ & wind velocity $(\mathrm{m} / \mathrm{s})$ \\
\hline & Cartesian coordinate \\
\hline \multicolumn{2}{|c|}{ Greek Symbols } \\
\hline
\end{tabular}




\begin{tabular}{|c|c|}
\hline$\Delta$ & difference \\
\hline$\rho$ & density, $\mathrm{kg} / \mathrm{m}^{3}$ \\
\hline$\rho_{\text {eff }}$ & effective density of PCM/fin, $\mathrm{kg} / \mathrm{m}^{3}$ \\
\hline$\rho_{f}$ & density of fin, $\mathrm{kg} / \mathrm{m}^{3}$ \\
\hline$\rho_{g}$ & density of glass cover, $\mathrm{kg} / \mathrm{m}^{3}$ \\
\hline$\rho_{p}$ & density of PCM, $\mathrm{kg} / \mathrm{m}^{3}$ \\
\hline$\rho_{w}$ & density of absorber plate, $\mathrm{kg} / \mathrm{m}^{3}$ \\
\hline$\delta_{a}$ & thickness of air, m \\
\hline$\delta_{g}$ & thickness of glass cover, $\mathrm{m}$ \\
\hline$\delta_{p}$ & thickness of PCM, m \\
\hline$\delta_{w}$ & thickness of absorber plate, $\mathrm{m}$ \\
\hline$\delta_{\text {ins }}$ & thickness of insulation material, $\mathrm{m}$ \\
\hline$\alpha_{g}$ & absorptance of glass cover \\
\hline$\alpha_{w}$ & absorptance of absorber plate \\
\hline$\sigma$ & Stefan-Boltzmann constant $\left(5.67 \cdot 10^{-8} \mathrm{~W} / \mathrm{m}^{2} \mathrm{~K}^{4}\right)$ \\
\hline$\varepsilon_{g}$ & emittance of glass cover \\
\hline$\varepsilon_{g}$ & emittance of absorber plate \\
\hline$\tau_{g}$ & transmittance of glass cover \\
\hline$\gamma$ & mean temperature approximation coefficient \\
\hline$v$ & kinematic viscosity $\left(\mathrm{m}^{2} / \mathrm{s}\right)$ \\
\hline$\beta$ & tilt angle, $\left({ }^{\circ}\right)$ \\
\hline \multicolumn{2}{|c|}{ Subscripts } \\
\hline$a$ & air inside solar chimney \\
\hline$a m b$ & ambient \\
\hline$c v$ & convection \\
\hline eff & effective \\
\hline$f$ & fin \\
\hline$g$ & glass cover cover \\
\hline$l$ & liquid \\
\hline ins & insulation material \\
\hline$p$ & phase change material \\
\hline$r$ & radiation \\
\hline$s$ & solid \\
\hline$t$ & total \\
\hline$w$ & absorber plate \\
\hline
\end{tabular}

\section{Introduction}

The continuous increase in the greenhouse gas emissions and the depletion in the fossil fuels at an alarming rate is the main driving force to more effectively utilize new kinds of renewable energy. One of the options is to develop effective energy storage technologies which is as important as developing new sources of energy [1]. A good designed energy storage technology would not only reduce the mismatch between the energy supply and demand but also improve the efficiency and reliability of the systems $[2,3]$. As a prospective energy storage method, latent heat storage (LHS) has been attracting 
more attentions. The most attractive advantages of the LHS are the high-energy storage density and constant storing/releasing temperature corresponding to the phase transition temperature of the phase change material (PCM) [4]. Generally, the LHS offers the following advantages [5, 6]: reduced energy consumption, improved indoor air quality, increased flexibility of operation, decreased equipment size, enhanced efficiency and effectiveness of equipment utilization, conservation of fossil fuels, and reduced pollutant emissions, e.g. $\mathrm{CO}_{2}$ and $\mathrm{CFCs}$.

Being a simple and practical strategy, solar chimney has been regarded as an attractive passive cooling and heating design. Solar chimney is an air channel to generate the driving force through the thermal buoyancy, which is created by the solar energy in results of a temperature rise as well as a density drop in the air within the solar chimney [7]. The thermal performance of solar chimney has been experimentally and/or numerically investigated extensively [8-11]. The results showed that solar chimney has great potential to reduce energy consumption and therefore ultimately, reduce the air pollution and greenhouse gas emissions. However, the inherent disadvantage of the solar chimney which limits its application in space heating is its incapability to work during night-time or cloudy day. It is because of the low thermal storage capacity of the conventional storage materials such as concrete, brick and metal, etc. used in the conventional solar chimney design. Besides, the outlet air temperature varies with absorber temperature that would greatly impact the indoor thermal comfort level. All of these drawbacks can be greatly alleviated with the advantages of the PCM. PCM can replace the conventional storage material and store the solar energy gained from the absorber.

Stritih and Novak [12] designed an experimental solar wall for storing the solar heat through the black paraffin wax with a melting temperature range of $25 \sim 30^{\circ} \mathrm{C}$. The stored heat was used for heating and ventilation of a house. The experimental results indicated that the LHS stores heat at a relatively constant temperature and the energy thus lost to the surroundings is lower than that of the conventional sensible heat storage system. They also found that the temperature of the outlet air delivered from the solar wall is relatively constant. The thermal performance of a ventilated double skin façade (DSF) with PCM during the heating season was experimentally studied by Gracia et al. [13]. Two identical houselike cubicles located in Puigverd de Lleida (Spain) were monitored during winter. A ventilated facade with PCM was located at the south wall of one of the cubicles. The ventilated facade acted as a solar 
collector during the solar absorption period, and then discharged the solar energy to the indoor environment when it was required. The experimental results concluded that the use of the ventilated facade with PCM significantly improves the thermal behaviour of the whole building (working as a heat supplier in free floating tests and reducing significantly the electrical consumption of the HVAC systems). Therefore the previous work indicates that the application of the PCM in a solar heating system is very promising.

It is also important to highlight that the PCM does have a great influence on the performance of a LHS system, Therefore, a parametric study is required to gain a further insight into a PCM based solar chimney. The objective of this paper is to experimentally and numerically investigate the impact of the design parameters on the thermal performance of a PCM based solar chimney system. In this paper, the effect of several design parameters of the solar chimney on the melting and freezing times, airflow rate and air temperature difference between inlet and outlet air are studied. The investigated parameters of the system include the latent heat of fusion, heat flux, thermal conductivity of the insulation material, absorptivity of the absorber plate, transmissivity of the glass cover, inlet air temperature and the thermal conductivity of the absorber. Moreover, how the parameters affect the absorber surface temperature is also discussed in this study.

\section{Experimental system description}

\subsection{Test rig setup}

Fig. 1 shows the schematic diagram of the testing rig for the experimental study. The experimental solar chimney consists of a glass cover, a PCM container, an air channel and two openings. The air channel has the internal dimensions of $2000 \mathrm{~mm}$ high, $1000 \mathrm{~mm}$ wide and $200 \mathrm{~mm}$ deep, and the side walls of the chimney are constructed from timber and thermally insulated by polystyrene board to reduce the heat loss. An opening along the top façade of the LHS unit is designed as the air outlet and another opening at the bottom acts as the air inlet. The inlet and outlet have the same dimensions of $1000 \mathrm{~mm}$ wide and $200 \mathrm{~mm}$ high. A rectangular PCM container with the dimensions of $1000 \mathrm{~mm}$ wide $\times 1600 \mathrm{~mm}$ high $\times 40 \mathrm{~mm}$ deep is constructed by using stainless steel. A total of $50 \mathrm{~kg}$ PCM is macroencapsulated inside the container. Technical grade paraffin wax RT42 from Rubitherm is chosen as the 
working PCM in this study due to its suitable thermo-physical properties as listed in Table 1. As shown in Fig.3 (a), in order to accelerate the charging and discharging processes of the PCM, 30 straight fins made of stainless steel are designed as the thermal conductivity enhancer and each fin has the following dimensions: $1000 \mathrm{~mm}$ long, $40 \mathrm{~mm}$ high and $1 \mathrm{~mm}$ thick. Each two fins are spaced by $50 \mathrm{~mm}$ so that the whole PCM is cut into smaller layers. The front wall of the container is painted into black as the high thermal absorptive absorber. Except the front side, all the other five sides of the PCM container are well insulated.

There are two different operating modes are considered in this paper: 1) Vents closed operating condition. Generally, the residential building is not occupied during the daytime, and the indoor temperature is high enough to maintain the indoor thermal comfort when the solar irradiation available. The chimney is closed to maximize the storage of the solar energy; 2) Vents open operating condition. The indoor air enters the inlet, and passes through the air channel where it will be heated up by the absorber plate and then flows into the living space.

\subsection{Monitoring parameters and positions}

Monitoring parameters and positions are given in Fig.2. A total of 39 calibrated K-type thermocouples with an accuracy of $\pm 0.3{ }^{\circ} \mathrm{C}$ are distributed on the glass cover, absorber plate, inside the PCM and the air channel. $9 \mathrm{~K}$-type thermocouples are distributed to measure the temperature profiles across the depth along the vertical centre-line of the chimney, whereas 3 thermocouples are evenly placed at the vertical centre-line of the inlet. The average temperature from the three measurements was calculated as the inlet temperature. The same method is applied to determine the outlet air temperature. To measure the temperature distribution of absorber surface, 12 thermocouples are fixed onto the surface evenly. The external surface temperature of glass cover is determined by another 3 thermocouples. The thermocouples are inserted inside reflective aluminium shields to reduce the measurement error as much as possible.

In order to measure the temperature profiles inside the PCM and determine the melting and freezing times, 9 thermocouples are inserted into the PCM at three different heights. As shown in Fig.3, every three thermocouples are distributed at 5,20 and $35 \mathrm{~mm}$ away from the absorber surface at each height 
respectively.

When all thermocouples inside the paraffin record the same room temperature, this is treated as the initial melting condition. As shown in Fig.1, the inlet and outlet are closed during the charging period. Once the charging period is finished, the heat discharging period starts. The inlet and outlet would be opened to drive the air flowing through the air channel where it is heated up by the absorber plate. All monitored data are automatically recorded in a Personal Computer (PC) through a data logger (DT85) at an interval of $20 \mathrm{~s}$

In order to generate the solar radiation flux, a solar simulator has been designed as the heat source in this experiment. The multiple-lamp solar simulator is made up of a two-dimensional wooden structure on which 14 tungsten halogen lamps of 400-W each are fixed. The tungsten halogen lamp generates a spectrum similar to that of the solar light. These lamps were installed in a staggered form in an area of $1.8 \mathrm{~m}$ long by $1 \mathrm{~m}$ wide. The heat flux produced by the simulator system can be varied by changing the distance between the system and heat absorber to meet the research requirement.

\section{Theoretical model and validation}

A mathematical model of the experimental setup is developed for the simulation of the thermal performance of the solar chimney by changing the design and operating parameters. The following simplifications have been made while writing equations for modelling.

\subsection{Assumptions}

In order to simplify the mathematical model, the following assumptions were made:

- One-dimensional heat transfer has been assumed for all energy transfer processes through the glass cover, air channel, absorber plate and the PCM.

- The PCM behaves ideally, i.e. such phenomena as property degradation and super-cooling are not accounted for.

- Thermophysical properties of the PCM for the solid and liquid phases are independent of temperature.

- The PCM is homogeneous isotropic. 
- Natural convection in the liquid phase of PCM has been ignored.

- The air channel of the system is well sealed when the openings are closed, i.e. no airflow occurs inside it.

- The temperature of the air is uniform at any cross-section of the air channel, but may vary along the flow direction.

- The air is treated as a perfect gas with the density linearly dependent on the temperature over the working temperature range.

With the above simplifications, heat transfer process between each major component of the solar chimney in closed mode during charging process and in open mode during discharging process can be described as follows.

\subsection{Closed theoretical mode \\ The glass cover}

Energy balance of the glass cover reveals that the glass receives energy in the form of solar radiation and radiation from the absorber while it loses energy in the form of convection to air in the solar channel and overall heat loss from glass to ambient. Energy transfer through the glass cover therefore can be written as follows:

$\rho_{g} C_{g} \delta_{g} A_{g} \frac{d T_{g}}{d t}=\alpha_{g} q_{s} A_{g}+h_{r, w-g}\left(T_{w}-T_{g}\right) A_{w}-h_{c v, g-a}\left(T_{g}-T_{a}\right) A_{g}-U_{t}\left(T_{g}-T_{a m b}\right) A_{g}$

\section{The trapped air}

The heat-balance equation of the air trapped between the glass cover and absorber is expressed as [15]:

$\rho_{a} C_{a} \delta_{a} A_{a} \frac{d T_{a}}{d t}=h_{c v, g-a}\left(T_{g}-T_{a}\right) A_{a}+h_{c v, w-a}\left(T_{w}-T_{a}\right) A_{a}$

\section{The absorber plate}



gradients across the thickness of the absorber material are negligible. Consequently, a one-dimensional analysis can be employed.

$\rho_{w} C_{w} \delta_{w} A_{w} \frac{d T_{w}}{d t}=\tau_{g} \alpha_{w} q_{s} A_{w}-h_{r, w-g}\left(T_{w}-T_{g}\right) A_{w}-h_{c v, w-a}\left(T_{w}-T_{a}\right) A_{w}-h_{w-p}\left(T_{w}-T_{p}\right) A_{w}$

The method employed in the current work is based on the effective heat capacity formulation, in

which the latent heat is approximated by a large heat in sensible form over the phase change temperature interval, $\left(T_{2}-T_{1}\right)$. The effective heat capacity of the PCM $\left(C_{e f f}\right)$ is directly proportional to the energy stored and released during the phase change but inversely proportional to the interval of the melting or solidification temperature range. During the phase change, the heat capacity of the PCM is given as follows [16]:

$C_{e f f}=\left\{\begin{array}{crl}C_{p, s} & T<T_{1} & \text { solid } \\ \frac{h}{T_{2}-T_{1}}+C & T_{1} \leq T \leq T_{2} & \text { mushy } \\ C_{p, l} & T>T_{2} & \text { liquid }\end{array}\right.$

PCM/fin mixture 
phenomenon because of the existence of the fins and different phases of PCM (solid, mushy or liquid phase) during the charging or discharging process. This will require separate energy equations for different components and phases. Hence an approximate thermo-physical property method was experimentally verified by Chow et al. [17], and is applied in this study. Approximating the thermophysical properties of the mixture can simplify the simulation process, and the average properties of the mixture based on the volume rate of the PCM and fins unit are used in this numerical simulation. With this assumption, the entire domain of PCM and fins component is treated as a single phase with modified properties governed by one set of conservation equations [18]. The computing equations for the average thermo-physical properties are expressed as [18]:

$k_{e f f}=\frac{k_{f} V_{f}+k_{p} V_{p}}{V}$

$\rho_{\text {eff }}=\frac{\rho_{f} V_{f}+\rho_{p} V_{p}}{V}$

$218 C_{e f f}=\left\{\begin{array}{lr}\frac{C_{f} V_{f}+C_{p, s} V_{p}}{V} & \text { solid PCM } \\ \frac{C_{f} V_{f}+(L / \Delta T) V_{p}}{V} & \text { mushy PCM } \\ \frac{C_{f} V_{f}+C_{p, l} V_{p}}{V} & \text { liquid PCM }\end{array}\right.$

The PCM is encapsulated by a metallic container, and the absorber plate serves as heat exchanger, good thermal contact between the PCM and the container is assumed. As shown in Figure 4, the PCM container is divided to $\mathrm{n}(\mathrm{n}=20)$ cells along the thickness of the container. In terms of the definition of the effective heat capacity, the one dimensional energy equation of the PCM for an internal node "i ", can be expressed as: 


$$
\left\{\begin{array}{lr}
\rho_{e f f} c_{e f f} d x A_{w} \frac{d T_{p, i}}{d t}=h_{w-p}\left(T_{w}-T_{p, i}\right) A_{w}-\frac{k_{e f f}}{d x}\left(T_{p, i}-T_{p, i+1}\right) A_{w} & i=1 ; \\
\rho_{e f f} c_{e f f} d x A_{w} \frac{d T_{p, i}}{d t}=\frac{k_{e f f}}{d x}\left(T_{p, i-1}-T_{p, i}\right) A_{w}-\frac{k_{e f f}}{d x}\left(T_{p, i}-T_{p, i+1}\right) A_{w} & i=2,3, \cdots \cdots n-1 ; \\
\rho_{e f f} c_{e f f} d x A_{w} \frac{d T_{p, i}}{d t}=\frac{k_{e f f}}{d x}\left(T_{p, i-1}-T_{p, i}\right) A_{w}-U_{\text {ins }}\left(T_{p, i}-T_{a m b}\right) A_{w} & i=n ;
\end{array}\right.
$$

\subsection{Open theoretical mode}

Once the charging period finishes, the solar simulator is turned off and the inlet and outlet will be opened, meaning the discharging period begins. The air passes through the air cavity, exchanges the heat with the absorber plate, and then flows back to the surroundings through the outlet. The energy balance for various components of the system during the discharging period is presented as below:

The glass cover

follows:

$\rho_{g} C_{g} \delta_{g} A_{g} \frac{d T_{g}}{d t}=h_{r, w-g}\left(T_{w}-T_{g}\right) A_{w}+h_{c v, a-g}\left(T_{a}-T_{g}\right) A_{g}-U_{t}\left(T_{g}-T_{a m b}\right) A_{g}$

Heat transfer analysis of the absorber plate considering the air flow is provided below:

$\rho_{w} C_{w} \delta_{w} A_{w} \frac{d T_{w}}{d t}=h_{p-w}\left(T_{p}-T_{w}\right) A_{w}-h_{r, w-g}\left(T_{w}-T_{g}\right) A_{w}-h_{c v, w-a}\left(T_{w}-T_{a}\right) A_{w}$

The working fluid - air 
251 The relationship between air inlet temperature and air outlet temperature can be described as below

252

253

254

255

256

257

258

259

260

261

262

263

264

265

266

267

268

269

270

271

272

273

274

275

[18]:

$\mathrm{T}_{\mathrm{air}}=\gamma \mathrm{T}_{\mathrm{i}}+(1-\gamma) \mathrm{T}_{\mathrm{o}}$

In the above equation, $\gamma$ is the mean temperature approximation coefficient, the value of 0.74 has been suggested by Ong and Chow [19]; $\mathrm{T}_{\text {air }}$ is the mean temperature inside channel, ${ }^{\circ} \mathrm{C}$.

Airflow rate

The airflow rate generated by the buoyancy can be calculated by the following equation [20]:

$m=\frac{C_{d} \rho_{a} A_{o}}{\sqrt{1+\left(A_{o}^{2} / A_{i}^{2}\right)}} \sqrt{2 g L\left(\frac{T_{a i r}}{T_{i}}-1\right)}$

\section{$\underline{3.4 \text { Expression of heat transfer coefficient }}$}

The radiation heat transfer coefficient between the absorber and glass cover has been obtained from [20]:

$$
h_{r, w-g}=\sigma\left(T_{w}^{2}+T_{g}^{2}\right)\left(T_{w}+T_{g}\right) /\left(1 / \varepsilon_{w}+1 / \varepsilon_{g}-1\right)
$$

Assuming the natural convection of the air between two parallel planes, the convective heat transfer coefficient $h_{c v, g-a}$ between the glass cover and the layer of draped air is calculated by using the following equations [15].

$$
h_{c v, g-a}=h_{c v, w-a}=N u k_{a} / \delta_{a}
$$


277 The Nusselt number, $\mathrm{Nu}$ is given by the following relation [15]

278

$N u=[0.06-0.017(\beta / 90)] G r^{1 / 3}$

280

281

where $\beta$ is the inclined angle of the absorber plate and the Grashoff number is

282

283

$G r=g\left|T_{w}-T_{g}\right| \delta_{a}^{3} / v^{2} T_{a i r}$

284

285

Mean air temperature inside chimney is assumed to be equal to the average temperature between the 286

flat absorber and the absorber-side glass cover.

287

288

$T_{\text {air }}=\left(T_{w}+T_{g}\right) / 2$

$U_{t}$, the overall heat loss coefficient from the glass cover to ambient, including convection by wind and radiative heat transfer from glass cover to sky. This can be written as:

292

293

$$
U_{t}=h_{w i n d}+h_{r, g-s k y}
$$

294

295

296

The convective heat transfer coefficient between the glass cover and the ambient depends essentially on wind speed and can be calculate by [21]:

297

298

$$
h_{\text {wind }}=2.8+3.0 V_{\text {wind }}
$$

299

The radiative heat transfer coefficient from the glass surface to the sky referred to the ambient 301 temperature may be obtained from:

302 
where the sky temperature is $U_{\text {ins }}$ given by:

$$
U_{\text {ins }}=1 /\left(\delta_{\text {ins }} / k_{\text {ins }}+d x / 2 k_{e f f}+1 / h_{a}\right)
$$

\subsection{Solution of equations}

For the charging period, the PCM is initially solid and the whole system's temperature is assumed equal to the ambient temperature, $T_{a m b}$. The values for various initial conditions are given in Table 2 . For the discharging period, the PCM's temperature and the temperatures of various components depend on the final melting condition. The air inlet temperature equals to the ambient temperature, $T_{0}$. A code is developed within 'MATLAB' to determine the temperatures of $T_{w}, T_{g}, T_{p}, T_{a i r}$ as well as the airflow. The obtained mean air temperature, $T_{\text {air }}$ along with Eq. (13) can be used to obtain the air outlet temperature. With the developed program, the performance of the solar chimney combined with PCM and the related factors have been investigated under different conditions. 
A series of experiments are carried out under the identical experimental conditions to verify the mathematical model and ensure the accuracy of simulations. The model is set up to reproduce the experimental conditions and the same PCM and specifications of the experimental setup are employed in the numerical model. The obtained numerical results of melting and freezing times of the PCM, absorber surface temperature, airflow rate and air temperature difference $\Delta \mathrm{T}$ between the inlet and outlet air are compared with the those of the experimental results for a uniform heat flux of $q=700 \mathrm{~W} / \mathrm{m}^{2}$. As shown in Fig.5, it is clear that good agreements between the numerical and experimental results are observed. This coherence shows that the developed numerical model is acceptable and reliable.

It also can be seen from Fig.5 (c) and (d), the airflow rate and outlet air temperature difference vary in a small range during the period which is dominated by latent heat. The little variations in airflow rate and outlet temperature are the advantages for the design of such a solar air heating system, because the heated air delivered from the solar chimney can be supplied to a living space with a comfortable condition during the discharging period.

\section{Results and discussion}

With the verified numerical model, the study on the effect of a number of design and operational parameters on the thermal performance of the system is carried out. For the heating application, four most important quantities are considered to evaluate the thermal performance of the system. They are the melting/freezing time, absorber surface temperature, airflow rate and inlet and outlet air temperature difference $\left(\Delta T=T_{o}-T_{i}\right)$. For a LHS system design, the time taken for the whole PCM to melt or solidify is one crucial factor. Airflow rate is a direct measure of how much warm air is delivered into the living space. Air temperature difference and the absorber surface temperature indicate how much the air temperature is elevated after heated by absorber surface. The simulation conditions for the following parametric cases are given in Table 3.

\subsection{Effect of latent heat of fusion}

The considered values of the latent heat of fusions are 70,120 and $170 \mathrm{~kJ} / \mathrm{kg}$, respectively. As presented in Fig.6 (a), the latent heat of fusion has a great effect on the melting and freezing times. The 
larger the latent heat of fusion, the longer melting and freezing times. The melting times are $3.2 \mathrm{~h}, 4.6$ $\mathrm{h}$ and $6.5 \mathrm{~h}$ accordingly, while the freezing times are $10 \mathrm{~h}, 13.5 \mathrm{~h}$ and $16 \mathrm{~h}$, respectively. It is seen that the effect of the latent heat of fusion on melting time is more significant than that on freezing time. Moreover, the latent heat of fusion greatly affects the absorber surface temperature during the melting and freezing processes (Fig.6 (b)). The increase in absorber surface temperature is significantly higher during the melting period with comparison to the freezing period. Higher latent heat will absorb more thermal energy with less sensible heat results in increasing the absorber surface temperature. And then the absorber surface temperature for lower latent heat of fusion drops faster than higher ones. The variation trends of the absorber surface temperature are similar with those of PCM temperature. Fig.6 (c) and (d) show the effects of latent heat of fusion on airflow rate and air temperature difference during the discharging period. As expected, the airflow rate and temperature difference with lower latent heat of fusion are higher at the initial freezing period but much lower after 6 hours releasing period. The larger latent heat of fusion will lead longer heating period with constant airflow rate.

\subsection{Effect of heat flux}

The heat fluxes under consideration are $\mathrm{q}=600 \mathrm{~W} / \mathrm{m}^{2}, 700 \mathrm{~W} / \mathrm{m}^{2}$ and $800 \mathrm{~W} / \mathrm{m}^{2}$, respectively. As displayed in Fig.7 (a), the melting times are 8.8 h, $6.5 \mathrm{~h}$ and $5.6 \mathrm{~h}$, respectively, while the freezing time is $15 \mathrm{~h}, 17 \mathrm{~h}$ and $18 \mathrm{~h}$ accordingly. That is, a higher heat flux increases the heat transfer rate during the melting period and therefore shortens the melting time, and a higher heat flux induces more sensible heat stored which prolongs the freezing time. As the charge period is limited by the period of solar energy availability, this parameter of heat flux is an important factor to determine the efficiency of the system in terms of melting and freezing time. Similarly, it is seen in Fig.7 (b) that the higher heat flux results in the higher absorber surface temperature during the melting period but not remarkable for freezing period. For instance, the surface temperature for heat flux of $800 \mathrm{~W} / \mathrm{m}^{2}$ is only slightly higher than $700 \mathrm{~W} / \mathrm{m}^{2}$ during freezing period.

Fig.7 (c) and (d) present the simulation results of the airflow rate and air temperature difference during the discharging period, respectively. The airflow rate and temperature difference both follow a similar pattern i.e. the values of initial airflow rate and temperature difference are high and then drop 
sharply at a very short period, then are followed by a long constant period during which the airflow and temperature difference are relatively stable, and a dramatically decrease in the airflow rate and temperature difference at the late period of freezing. As seen, the airflow rate and air temperature difference increase with the applied heat flux raise but is not outstanding.

\subsection{Effect of inlet air temperature}

The predicted melting and freezing times for various air inlet temperatures $15{ }^{\circ} \mathrm{C}, 20{ }^{\circ} \mathrm{C}$ and $25{ }^{\circ} \mathrm{C}$ under identical conditions are presented in Fig.8 (a). It is seen that the melting time is around $6.6 \mathrm{~h}$, the effect of air inlet temperature on the melting time can be ignored, since there is no air flow rate occurs during charging period. However, it is found that the air inlet temperature has a great impact on freezing time. The lower inlet air temperature induces the shorter freezing time due to the increased heat transfer rate between the air and the absorber surface. As shown, the freezing times are $12.5 \mathrm{~h}, 16 \mathrm{~h}$ and $20.5 \mathrm{~h}$, accordingly. In the Fig.8 (b) it is seen clearly that the inlet air temperature affects the surface temperature more greatly especially during the freezing period. The lower inlet air temperature has a lower surface temperature due to the high temperature difference between inlet air and absorber surface leading to high heat transfer rate. Converse to the surface temperature, the lower inlet air temperature results in higher airflow rate and temperature difference displayed in the Fig.8(c) and (d). As the higher inlet air temperature will reduce the temperature difference between the air and the absorber surface, and then subdued the thermal buoyancy effect. The average airflow rates and air temperature differences are $0.041,0.039$ and $0.037 \mathrm{~kg} / \mathrm{s}$, and $2.3,2.0$ and $1.8{ }^{\circ} \mathrm{C}$ under the inlet temperature of 15,20 and 25 ${ }^{\circ} \mathrm{C}$, respectively.

Although the lower inlet temperature increases the airflow rate and temperature difference, the desired working time, namely within the initial sensible and latent heat discharge periods of freezing is also reduced greatly. After a relative steady period, the heat transfer rate between the air and surface plate drops quickly resulting in low airflow rate and temperature difference to meet the heating purpose.

\subsection{Effect of absorber thermal conductivity}

Three metallic materials stainless steel, aluminium and copper are investigated in this study. The 
thermal conductivities of copper, aluminium and stainless steel are 401,226 and $16 \mathrm{~W} / \mathrm{m} \cdot{ }^{\circ} \mathrm{C}$, respectively. As shown in Fig. 9(a), the melting times for the absorber made of these three materials are $6.5 \mathrm{~h}, 6.3 \mathrm{~h}$, and $6 \mathrm{~h}$ respectively. The melting time is only shortened by $8 \%$ even the thermal conductivity of the absorber is increased by 25 times. And the thermal conductivity of the absorber hardly impacts the freezing time during the discharging period. This is because the wall of the absorber which is only $1 \mathrm{~mm}$, is very thin and the overall heat transfer coefficient is mainly dominated by the thermal conductivity of the PCM/fin mixture. Similar phenomenon is found in Fig. 9(b), the effects of thermal conductivities of absorber only affect the surface temperature during the melting period slightly but do not affect during freezing period. Fig.9 (c) and (d) present that the airflow rate and the outlet air temperature are scarcely affected by the thermal conductivity of the absorber when other parameters are kept constant.

\subsection{Effect of thermal conductivity of insulation material}

Fig.10 (a) and (b) show the effect of thermal conductivity $\left(0.02 \mathrm{~W} / \mathrm{m}{ }^{\circ} \mathrm{C}, 0.04 \mathrm{~W} / \mathrm{m}{ }^{\circ} \mathrm{C}\right.$ and $0.06 \mathrm{~W} / \mathrm{m}$ $\left.{ }^{\circ} \mathrm{C}\right)$ of the insulation material on the melting and freezing times and on absorber surface temperature. The melting times are $5.3 \mathrm{~h}, 6.6 \mathrm{~h}$ and $7.8 \mathrm{~h}$, and the freezing times are $18.5 \mathrm{~h}, 16.5 \mathrm{~h}$ and $14 \mathrm{~h}$, respectively. This indicates that the surrounding insulation situation can impact the energy storage and releasing heavily. The effects of thermal conductivity of the insulation material on airflow rate and temperature difference are shown in Fig.10 (c) and d, respectively. The airflow rate and air temperature

\subsection{Effect of transmissivity of glass cover}

The transmissivity of glass cover is another vital factor that directly impacts the incident solar radiation and the fraction of incident solar radiation directly transmits through the glass cover. Three values of transmissivities of glass cover, 0.8, 0.9, and 1.0, are given in this study. As seen in Fig.11 (a), 
$\mathrm{h}, 16.7 \mathrm{~h}$ and $16.8 \mathrm{~h}$, respectively. The results indicate that the transmissivity of the glass cover is an important factor in reducing the melting time while maintaining freezing time, as the charge period is limited by the period of solar energy availability. The effects of the transmissivity of the glass cover on the absorber surface temperature are similar to the melting and freezing times. The surface temperatures are greatly affected by the transmissivity of the glass cover during melting process whilst slightly affected by it during the freezing period as shown in the Fig.11 (b).

There is slightly influence in changing the transimmivity of the glass cover on the airflow rate and temperature difference at the initial and late freezing periods (Fig.11 (c) and (d)). The reason is that the higher transimmivity the larger amount of the heat stored in PCM during the melting period, which leads the higher airflow rate and outlet temperature.

\subsection{Effect of the absorptivity of the absorber surface}

Leon and Kumar [22] have proved that the absorptivity has a stronger effect on the efficiency of the absorber plate than emissivity. Liu et al. [23] has also confirmed that absorptivity of the absorber surface played an important role on solar absorber efficiency. This is because the absorptivity directly affects the total energy transferred to the PCM. However, all these results obtained from the investigations primarily focused on solar dryers or other solar heating applications, very few studies have been conducted on the effect of absorptivity on the thermal performance of solar chimney integrated with the PCM.

The absorptivities of the absorber surface studied are $0.8,0.9$ and 1.0. For these selected absorptivities (Fig.12 (a)) the melting times are around $7.6 \mathrm{~h}, 6.6 \mathrm{~h}$ and $5.6 \mathrm{~h}$, whilst the freezing times are $15.2 \mathrm{~h}$, $16.7 \mathrm{~h}$ and $20 \mathrm{~h}$ respectively. Therefore, increasing the absorptivity of the absorber plate will increase the heat transfer rate between the absorber and the PCM results in completing the melting process quicker. Increase in absorptivity leads to the higher surface temperature of absorber and results in more energy is stored in PCM (Fig.12 (b)). Consequent.ly, the freezing process is prolonged.

It is seen that increasing the absorptivity of the absorber surface will lift up the airflow rate and the outlet air temperature particularly at the initial and late freezing periods presented in the Fig.12(c) and (d). The airflow rates are slightly increased by around $0.01 \mathrm{~kg} / \mathrm{s}$ and $0.02 \mathrm{~kg} / \mathrm{s}$, and the temperature 
differences are increased by $0.7{ }^{\circ} \mathrm{C}$ and $1.4{ }^{\circ} \mathrm{C}$ for the absorptivity of 0.9 and 1.0 during phase change period.

\section{Conclusions}

A comprehensive numerical study on the thermal performance of a PCM based solar chimney has been carried out by using a validated mathematical model in this paper. The thermal performance of the solar chimney has been investigated by evaluation of the effect of seven design and operating parameters on the melting and freezing times, airflow rate, air temperature difference as well as the absorber surface temperature. The following conclusions can be drawn from the analysis:

1) The higher the latent heat of fusion the slower the melting/freezing process. For lower latent heat, the extra sensible heat stored in the PCM prolongs the freezing time. This can be stated that the effect of the latent heat of fusion on melting time is more significant than that on freezing time.

2) As expected, higher heat flux shortens the melting time, and brings more sensible heat which extends the freezing time. When the heat flux increases from 600 to $800 \mathrm{~W} / \mathrm{m}^{2}$, the melting time is reduced by $36.4 \%$, while the freezing time is increased by $20 \%$. With the specific climate, maximizing the heat flux from solar radiation will be crucial to enhance the thermal efficiency of the solar chimney with PCM.

3) The insulation material with a lower thermal conductivity can reduce the heat loss and improve the system thermal performance. Increasing the thermal conductivity from 0.02 to $0.06 \mathrm{~W} / \mathrm{m}{ }^{\circ} \mathrm{C}$, the melting time is prolonged by $47.2 \%$ and freezing time is decreased by $24.3 \%$. Therefore, in the practical application, excellent insulation of the system will be an effective method to improve the system thermal performance greatly with the least effort and cost.

4) Increasing the absorptivity of the absorber plate will enhance the heat transfer rate between the absorber surface and the PCM, and therefore the PCM completes melting process quicker. Consequently, the freezing process is prolonged. When the absorptivity of the absorber plate in increased from 0.8 to 1.0 , the melting time is decreased by $26.3 \%$, whilst the freezing time is 
increased by $3.16 \%$. The results suggest that the absorber plate with high absorptivity should be used in this proposed system in order to maximize the efficiency of solar absorber.

5) As expected, higher transmissivity of the glass cover allows more solar energy to be absorbed, and storing more energy within limited solar radiation time. However, when the transmissivity is increased by $25 \%$, the melting time is reduced by $26.7 \%$, while the freezing time is only increased by $1.8 \%$. Hence, the impact of transmissivity of the glass cover on freezing time is not obvious.

6) Lower inlet air temperature increases the heat transfer rate between the air and the absorber surface which results in a shorter freezing time and a higher air temperature difference between the inlet and outlet. When the inlet air temperature decreases from 25 to $15^{\circ} \mathrm{C}$, the freezing time is shortened by $39 \%$, and the air temperature difference is increased by $27.8 \%$.

7) The thermal conductivity of absorber plays slight effect on the system performance. The increase in the thermal conductivity of absorber from 16 to $401 \mathrm{~W} / \mathrm{m} \cdot{ }^{\circ} \mathrm{C}$, the melting time is only reduced by $8 \%$ and the freezing time is hardly affected. Hence, the conductivity of materials should not be considered as crucial selection factor.

\section{Acknowledgements}

This work is supported by National Science Foundation of China (No. 51478058) and Coventry University, UK. The authors are thankful to anonymous reviewers for their valuable comments and feedback.

\section{References}

[1]. Sharma A, V.V. Tyagi, C.R. Chen, D. Buddhi, Review on thermal energy storage with phase change materials and applications, Renewable and Sustainable Energy Reviews 2009;13:318-345.

[2]. Garg HP, Mullick SC, Bhargava AK. Solar thermal energy storage. D. Reidel Publishing Co; 1985. [3]. Project Report. Energy conservation through thermal energy storage, An AICTE project. 
[4]. Iten M, Liu S. A work procedure of utilizing PCMs as thermal storage systems based on air-TES systems, Energy Conversion and Management 2014; 77:608-627.

[5]. Dincer I, Rosen MA. Energetic, environmental and economic aspects of thermal energy storage systems for cooling capacity. Applied Thermal Engineering 2001; 21: 1105-1117.

[6]. Dincer I, Dost S, Li X. Performance analyses of sensible heat storage systems for thermal applications. International Journal of Energy Research 1997; 21: 1150-1171.

[7]. Zhai XQ, Song ZP, Wang RZ. A review for the applications of solar chimneys in buildings. Renewable and Sustainable Energy Reviews 2011 (15) 3757-3767.

[8]. Khedari J, Rachapradit N, Hirunlabh J. Field study of performance of solar chimney with airconditioned building. Energy 2003; 28:1099-1114.

[9]. Miyazaki T, Akisawa A, Kashiwagi T. The effects of solar chimneys on thermal load mitigation of office buildings under the Japanese climate. Renewable Energy 2006; 31: 987-1010.

[10]. Arce J, Jiménez MJ, Guzmán JD, Heras MR, Alvarez G, Xamán J. Experimental study for natural ventilation on a solar chimney. Renewable Energy 2009; 34:2928-2934.

[11]. Khedari J, Boonsri B, Hirunlabh J. Ventilation impact of a solar chimney on indoor temperature fluctuation and air change in a school building. Energy and Buildings, 2000; 32: 89-93.

[12]. Stritih U, Novak P. Thermal storage of solar energy in the wall for building ventilation. Second Workshop: IEA, ECES IA Annex 17. Advanced thermal energy storage techniques-feasibility studies and demonstration projects 2002; p.3-5.

[13]. Gracia A, Navarro L, Castell A, Ruiz-Pardo Á, Alvárez S, Cabeza LF. Experimental study of a ventilated facade with PCM during winter period. Energy and Buildings 2013; 58: 324-332.

[14]. RUBITHERM GmbH. Available from the prospectus 2013.

[15]. Hamed M, Fellah A, Brahim AB. Parametric sensitivity studies on the performance of a flat plate solar collector in transient behaviour. Energy Conversion and Management 2014; 78: 938947.

[16]. Lamberg P, Lehtiniemi R, Henell AM. Numerical and experimental investigation of melting and freezing processes in phase change material storage. International Journal of Thermal Sciences 2004; 43: 277-287. 
542 [17]. Chow L, Zhang J, Beam J. Thermal conductivity enhancement for phase change materials. 543 International Communications in Heat Mass Transfer 1996; 23(1): 91-100.

544 [18]. Alawadhi EM, Amon CH. PCM thermal control unit for portable electronic devices: 545 experimental and numerical studies. IEEE Transactions on components and packaging technologies $546 \quad 2003 ; 26(1): 116-125$.

547 [19]. Bansal NK, Mathur R, Bhandari MS. Solar chimney for enhanced stack ventilation. Building and Environment 1993; 28:373-377.

549 [20]. Ong KS. A mathematical model of a solar chimney. Renewable Energy 2003; 28:1047-60.

550 [21]. Duffie JA, Beckmann R. Solar engineering of thermal processes. New York: Wiley 551 Interscience; 1980.Leon MA, Kumar S. Mathematical modeling and thermal performance analysis 552 of unglazed transpired solar collectors. Solar Energy 2007; 81(1): 62-75.

553 [22]. Liu, T, Lin W, Gao W, Luo C, Li M, Zheng Q, Xia C. A parametric study on the thermal performance of a solar air collector with a V-groove absorber. International Journal of Green Energy 2007; 4(6): 601- 622. 
Fig.1. Schematic of the solar chimney combined with PCM: (a) closed mode; (b) open mode

Fig.2. Distributions of the thermocouples for the experimental testing (unit in $\mathrm{mm}$ ): (a) air channel; (b) absorber surface

Fig.3. Placement of the fins in PCM container and locations of the thermocouples inside the container (unit in $\mathrm{mm}$ ): (a) placement of fins; (b) lateral section; (c) cross section Fig. 4. Discretization domain for a one-dimensional phase change problem

Fig.5. Comparison of numerical and experimental results: (a) melting and freezing times; (b) absorber surface temperature; (c) airflow rate; (d) air temperature difference $\Delta \mathrm{T}$

Fig.6. Effect of different latent heat of fusions on: (a) melting and freezing times; (b) absorber surface temperature; (c) airflow rate; (d) air temperature difference $\Delta \mathrm{T}$ Fig.7. Effect of radiation heat flux on: (a) melting and freezing times; (b) absorber surface temperature; (c) airflow rate; (d) air temperature difference $\Delta \mathrm{T}$

Fig.8. Influence of inlet air temperature on: (a) melting and freezing times; (b) absorber surface temperature; (c) airflow rate; (d) air temperature difference $\Delta \mathrm{T}$

Fig.9. Effect of thermal conductivity of the container on: (a) melting and freezing times; (b) absorber surface temperature; (c) airflow rate; (d) air temperature difference $\Delta \mathrm{T}$ Fig.10. Effect of thermal conductivity of the insulation material on: (a) melting and freezing time; (b) absorber surface temperature; (c) airflow rate; (d) air temperature difference $\Delta \mathrm{T}$

Fig.11. Effect of transmissivity of the glass cover on: (a) melting and freezing times; 
(b) absorber surface temperature; (c) airflow rate; (d) air temperature difference $\Delta \mathrm{T}$

Fig.12. Effect of absorptivity of the absorber surface on: (a) melting and freezing times;

(b) absorber surface temperature; (c) airflow rate; (d) air temperature difference $\Delta \mathrm{T}$ 


\section{Table1}

Thermophysical properties of RT 42[14]

\begin{tabular}{ll}
\hline Thermophysical properties & Paraffin RT 42 \\
\hline Melting temperature $\left[{ }^{\circ} \mathrm{C}\right]$ & $38 \sim 43$ \\
Thermal conductivity $[\mathrm{W} / \mathrm{m} \mathrm{K}]$ & 0.2 \\
Heat of fusion $[\mathrm{kJ} / \mathrm{kg}]$ & 174 \\
Density $\left[\mathrm{kg} / \mathrm{m}^{3}\right]$ & 760 \\
Specific heat capacity $(\mathrm{kJ} / \mathrm{kg} \mathrm{K})$ & 2.0 \\
\hline
\end{tabular}

\section{Table 2}

Initial conditions for numerical modelling

\begin{tabular}{|c|c|c|c|c|c|}
\hline Parameters & Unit & Value & Parameters & Unit & Value \\
\hline PCM temperature & ${ }^{\circ} \mathrm{C}$ & 15 & Air inlet temperature & ${ }^{\circ} \mathrm{C}$ & 15 \\
\hline Heat flux & $\mathrm{W} / \mathrm{m}^{2}$ & 700 & Latent heat of fusion & $\mathrm{kJ} / \mathrm{kg}$ & 174 \\
\hline $\begin{array}{l}\text { Thermal conductivity of } \\
\text { the container }\end{array}$ & $\mathrm{W} / \mathrm{m}^{\circ} \mathrm{C}$ & 16 & $\begin{array}{l}\text { Thermal conductivity of } \\
\text { the insulator }\end{array}$ & $\mathrm{W} / \mathrm{m}{ }^{\circ} \mathrm{C}$ & 0.0361 \\
\hline $\begin{array}{l}\text { Thickness of insulation } \\
\text { material }\end{array}$ & $\mathrm{m}$ & 0.05 & $\begin{array}{l}\text { Transmissivity of } \\
\text { glazing }\end{array}$ & -- & 0.88 \\
\hline $\begin{array}{l}\text { Emittance of glass } \\
\text { cover }\end{array}$ & -- & 0.90 & $\begin{array}{l}\text { Emittance of the } \\
\text { absorber }\end{array}$ & -- & 0.94 \\
\hline $\begin{array}{l}\text { Absorptance of the } \\
\text { absorber }\end{array}$ & -- & 0.94 & Absorptance of the glass & -- & 0.06 \\
\hline
\end{tabular}


Table 3

Simulation conditions for different parametric cases

\begin{tabular}{|c|c|c|c|c|c|c|c|c|}
\hline Parameter & $\begin{array}{c}\text { Initial PCM } \\
\text { temperature } \\
\left({ }^{\circ} \mathrm{C}\right)\end{array}$ & $\begin{array}{c}\text { Inlet air } \\
\text { temperature } \\
\left({ }^{\circ} \mathrm{C}\right)\end{array}$ & $\begin{array}{c}\text { Heat } \\
\text { flux } \\
(\mathrm{W} / \mathrm{m} 2)\end{array}$ & $\begin{array}{c}\text { Latent heat } \\
\text { of fusion } \\
(\mathrm{kJ} / \mathrm{kg})\end{array}$ & $\begin{array}{c}\text { Thermal } \\
\text { conductivity of } \\
\text { absorber } \\
\left(\mathrm{W} / \mathrm{m} \cdot{ }^{\circ} \mathrm{C}\right)\end{array}$ & $\begin{array}{c}\text { Insulator thermal } \\
\text { conductivity } \\
\left(\mathrm{W} / \mathrm{m} \cdot{ }^{\circ} \mathrm{C}\right)\end{array}$ & $\begin{array}{c}\text { Transmissivity } \\
\text { of glazing }\end{array}$ & $\begin{array}{c}\text { Absorptivity of } \\
\text { the absorber } \\
\text { surface }\end{array}$ \\
\hline $\begin{array}{c}\text { Latent heat of } \\
\text { fusion }\end{array}$ & 20 & 20 & 700 & variable & 16 & 0.04 & 0.9 & 0.9 \\
\hline Heat flux & 20 & 20 & variable & 170 & 16 & 0.04 & 0.9 & 0.9 \\
\hline $\begin{array}{c}\text { Inlet air } \\
\text { temperature }\end{array}$ & 20 & variable & 700 & 170 & 16 & 0.04 & 0.9 \\
\hline $\begin{array}{c}\text { Absorber } \\
\text { thermal } \\
\text { conductivity }\end{array}$ & 20 & 20 & 700 & 170 & variable & 0.9 & 0.9 \\
\hline $\begin{array}{c}\text { Insulator } \\
\text { thermal } \\
\text { conductivity }\end{array}$ & 20 & 20 & 700 & 170 & 16 & variable & 0.9 \\
\hline $\begin{array}{c}\text { Transmissivity } \\
\text { of glazing }\end{array}$ & 20 & 20 & 700 & 170 & 16 & 0.04 & variable \\
\hline $\begin{array}{c}\text { Absorptivity of } \\
\text { the absorber }\end{array}$ & 20 & 20 & 700 & 170 & 16 & 0.04 & 0.9 \\
\hline
\end{tabular}




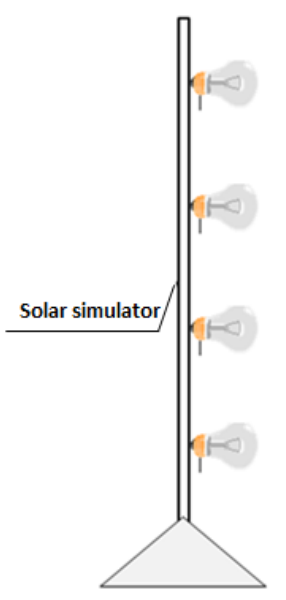

(a)
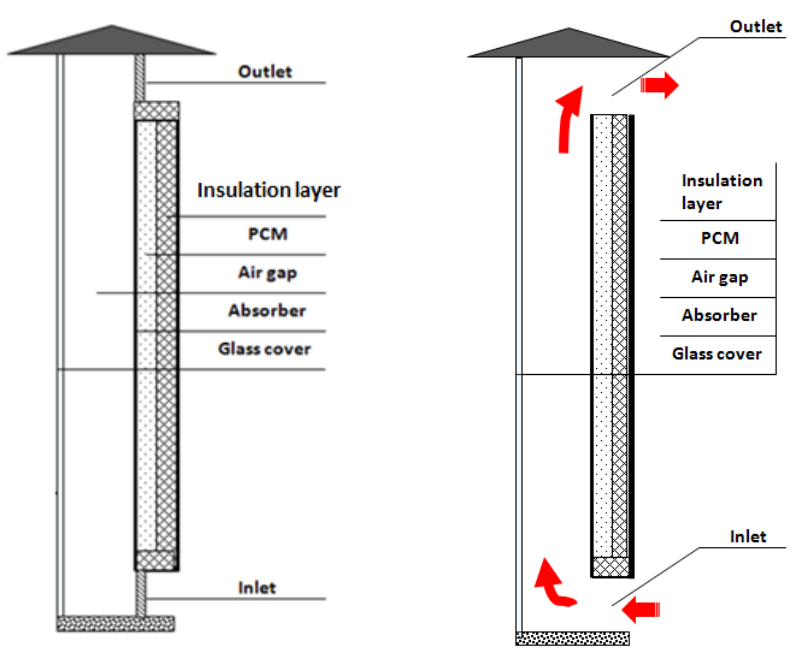

(b)

Fig.1. Schematic of the solar chimney combined with PCM: (a) closed mode; (b) open mode

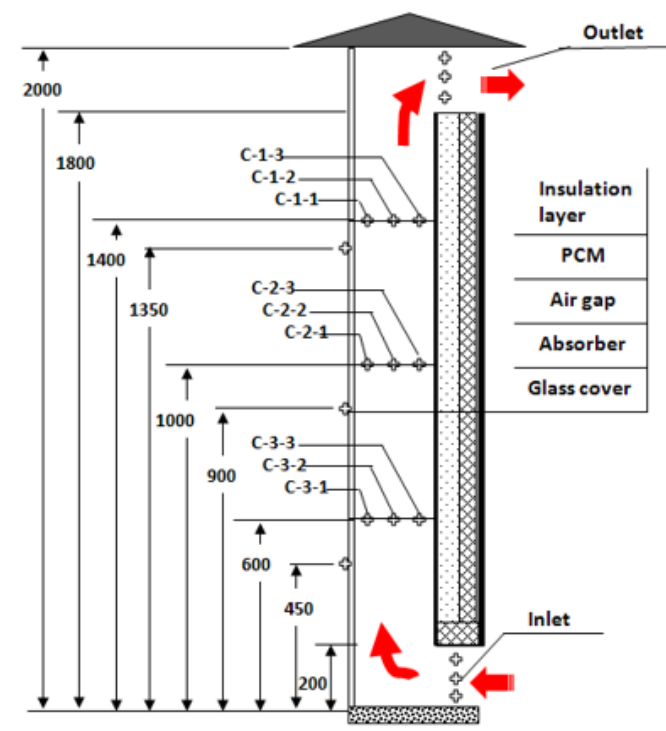

(a)

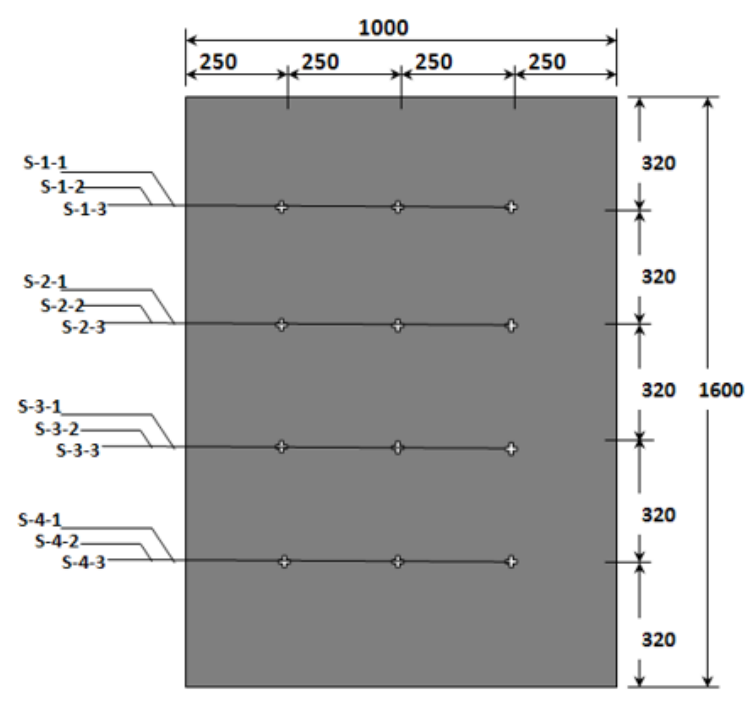

(b)

Fig.2. Distributions of the thermocouples for the experimental testing (unit in mm): (a) air channel; (b) absorber surface 


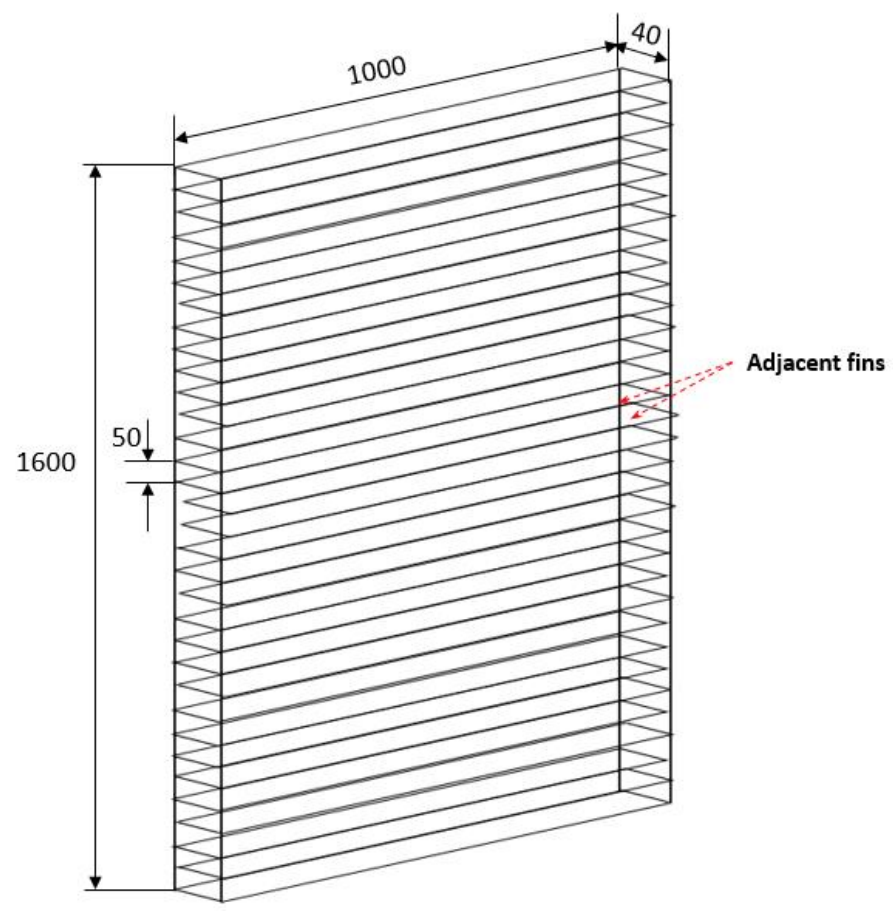

(a) Placement of the fins in PCM container

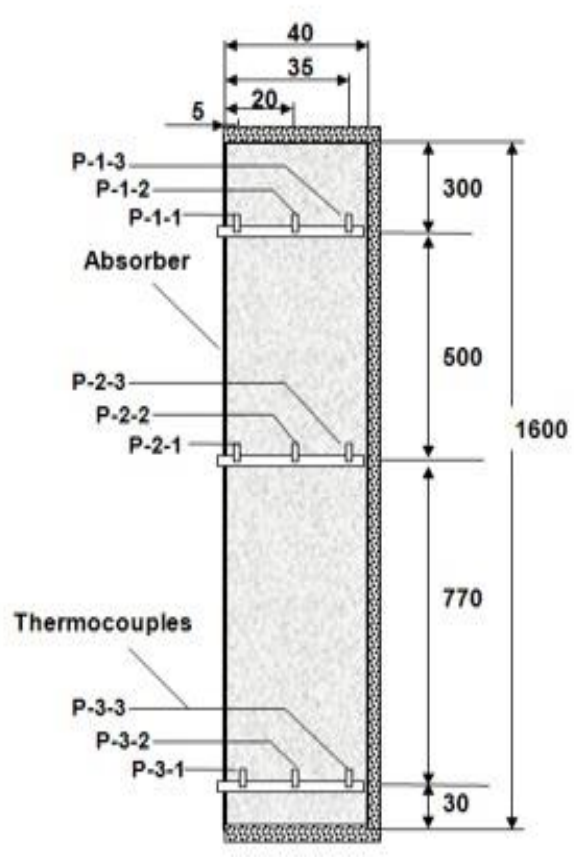

(b) Lateral section

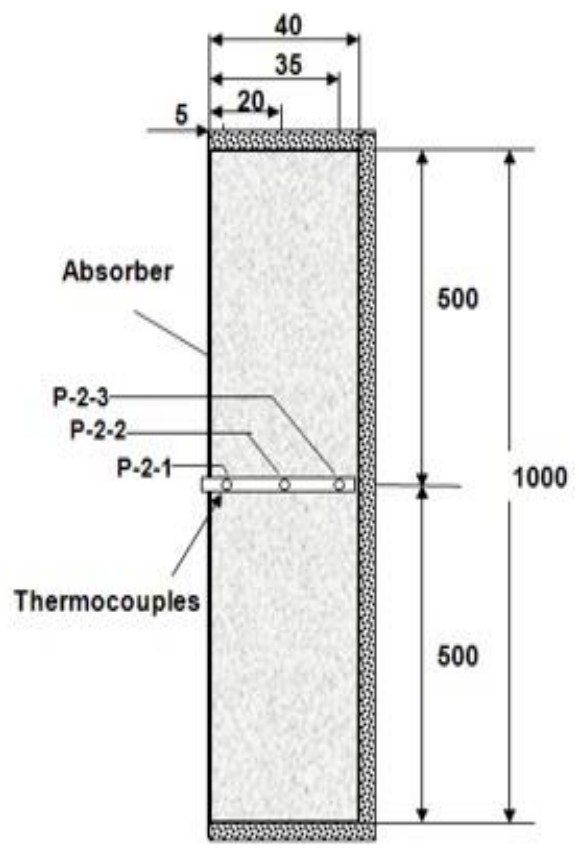

(c) Cross section

Fig.3. Placement of the fins in PCM container and locations of the thermocouples inside the container (unit in mm): (a) placement of fins; (b) lateral section; (c) cross section 


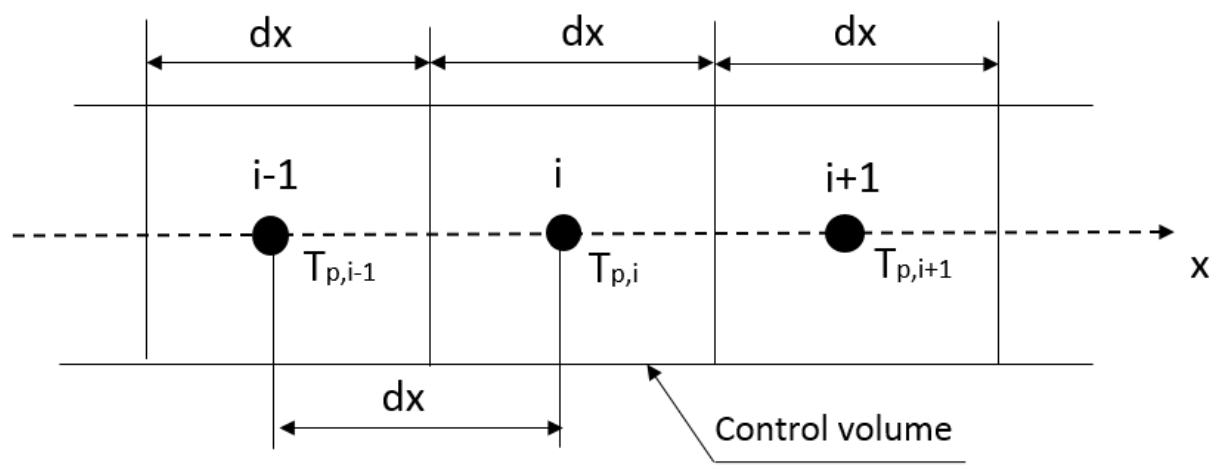

Fig. 4. Discretization domain for a one-dimensional phase change problem

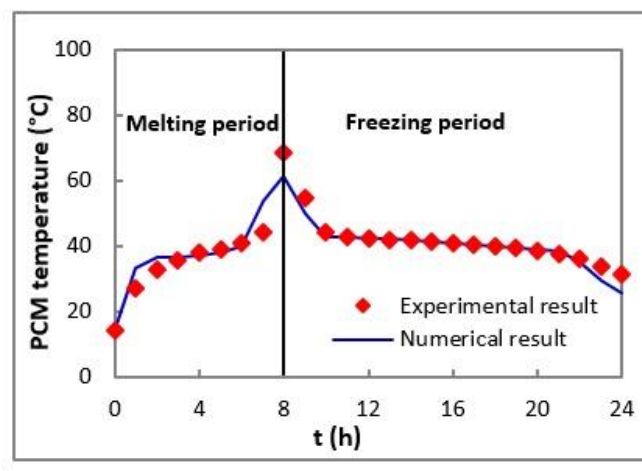

(a)

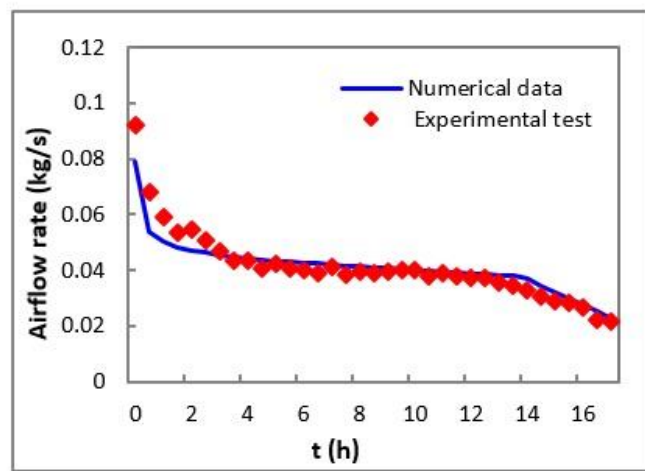

(c)

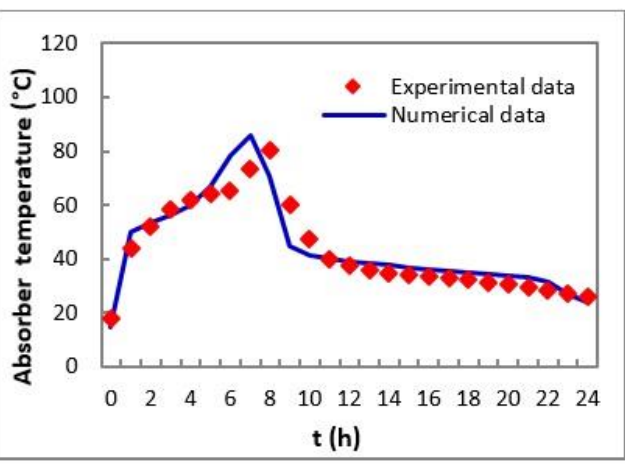

(b)

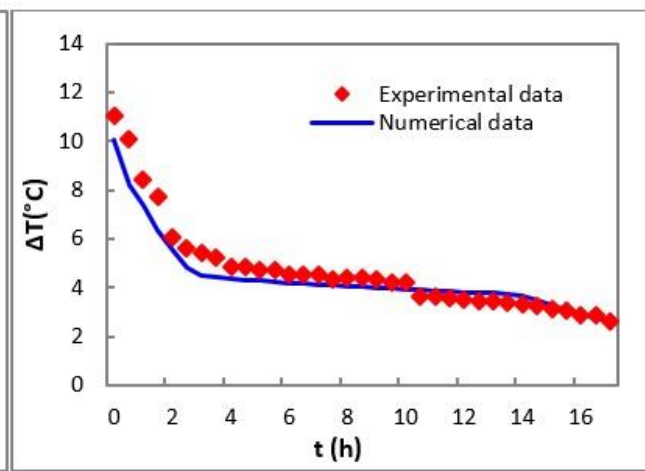

(d)

Fig.5. Comparison of numerical and experimental results: (a) melting and freezing times; (b) absorber surface temperature; (c) airflow rate; (d) air temperature difference $\Delta \mathrm{T}$ 


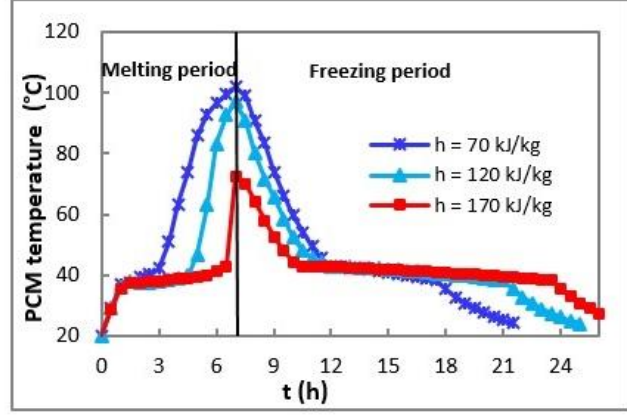

(a)

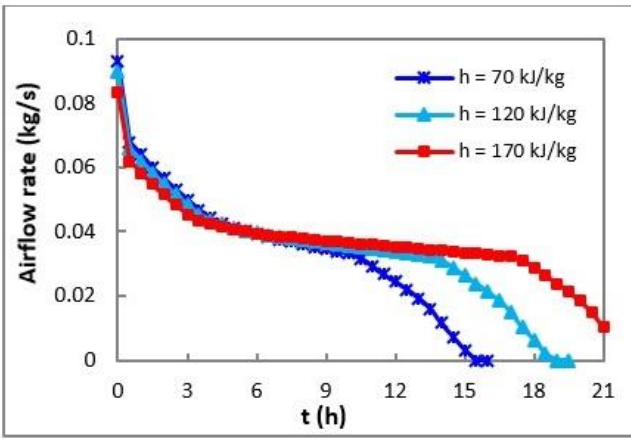

(c)

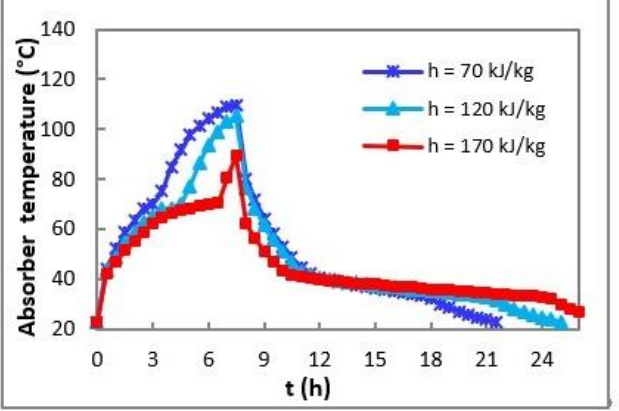

(b)

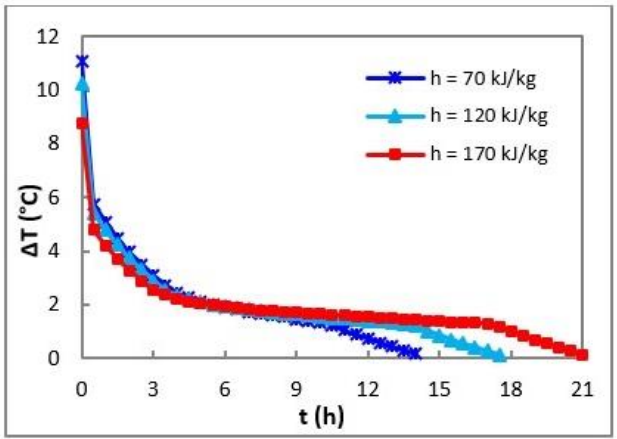

(d)

Fig.6. Effect of different latent heat of fusions on: (a) melting and freezing times; (b) absorber surface temperature; (c) airflow rate; (d) air temperature difference $\Delta \mathrm{T}$

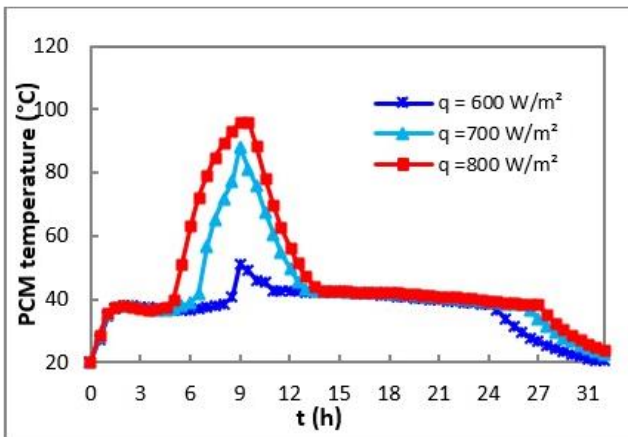

(a)

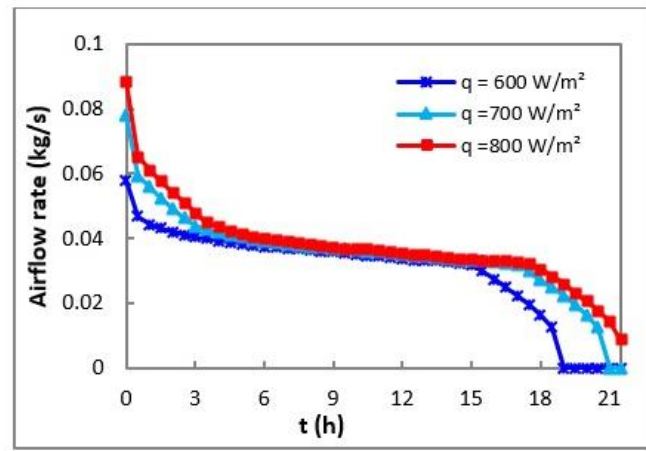

(c)

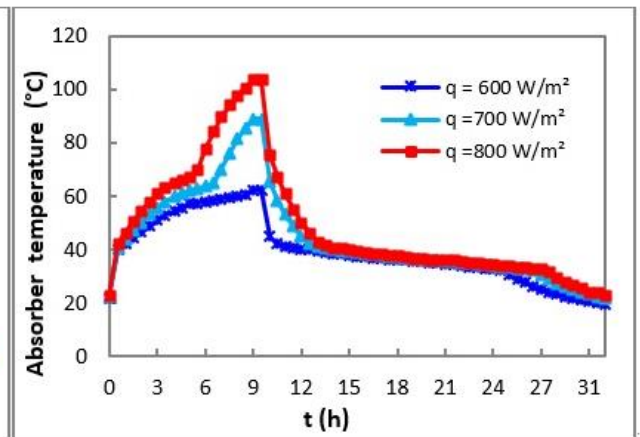

(b)

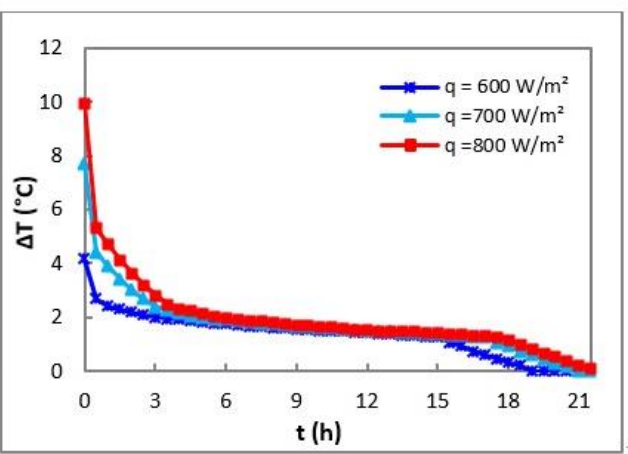

(d)

Fig.7. Effect of radiation heat flux on: (a) melting and freezing times; (b) absorber surface temperature; (c) airflow rate; (d) air temperature difference $\Delta \mathrm{T}$ 


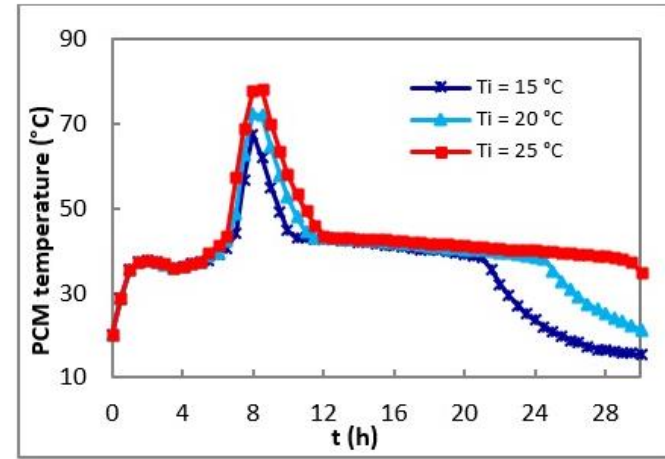

(a)

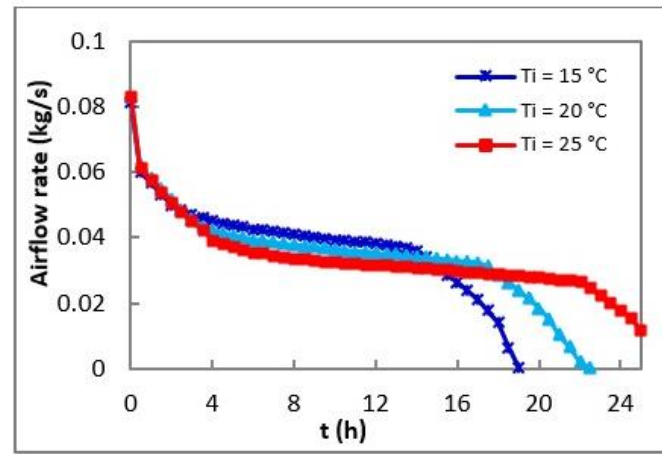

(c)

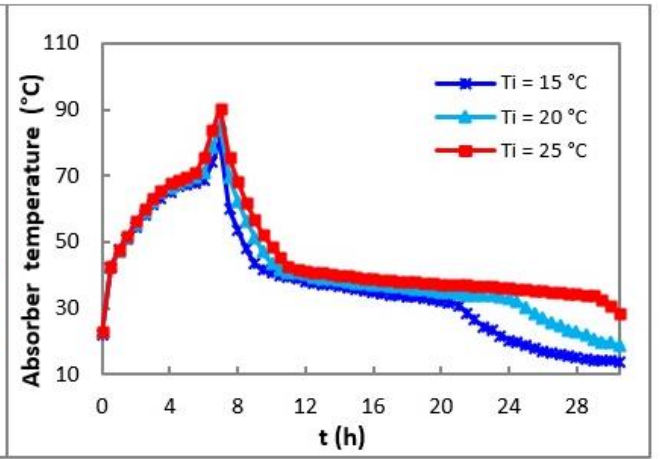

(b)

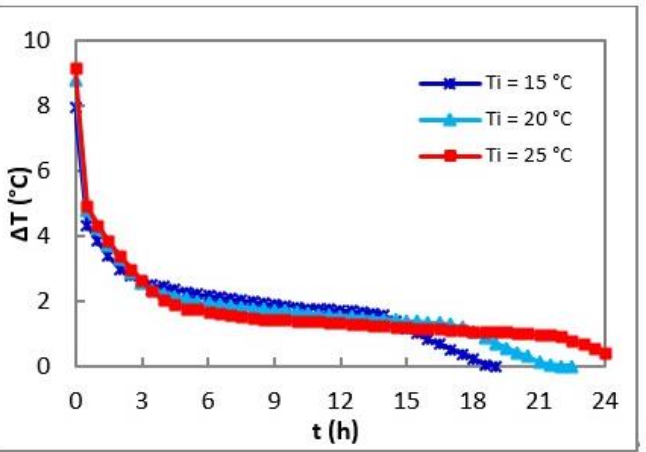

(d)

Fig.8. Influence of inlet air temperature on: (a) melting and freezing times; (b) absorber surface temperature; (c) airflow rate; (d) air temperature difference $\Delta \mathrm{T}$

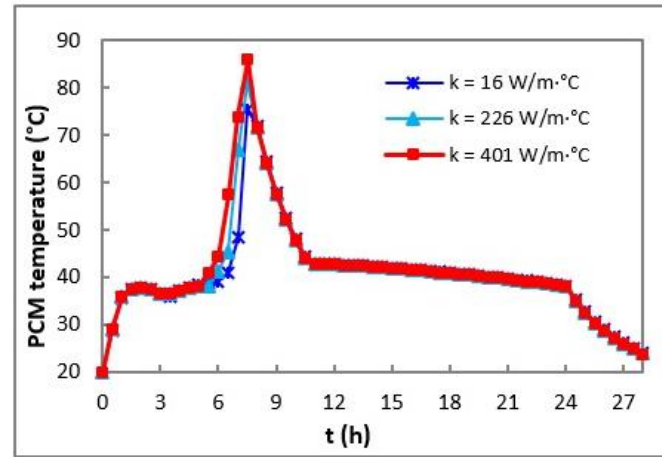

(a)

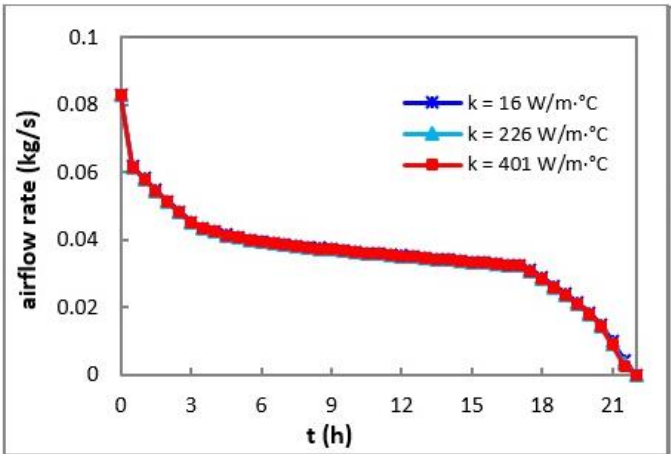

(c)

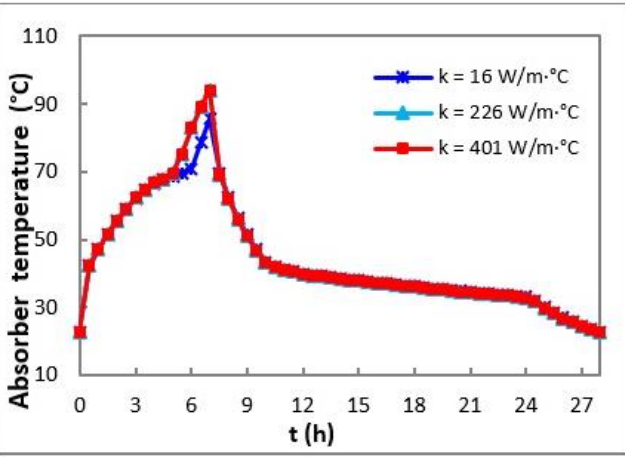

(b)

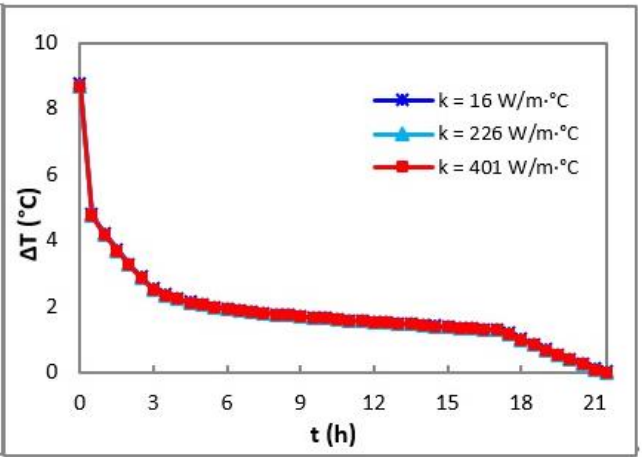

(d)

Fig.9. Effect of thermal conductivity of the absorber on: (a) melting and freezing times; (b) absorber surface temperature; (c) airflow rate; (d) air temperature difference $\Delta \mathrm{T}$ 


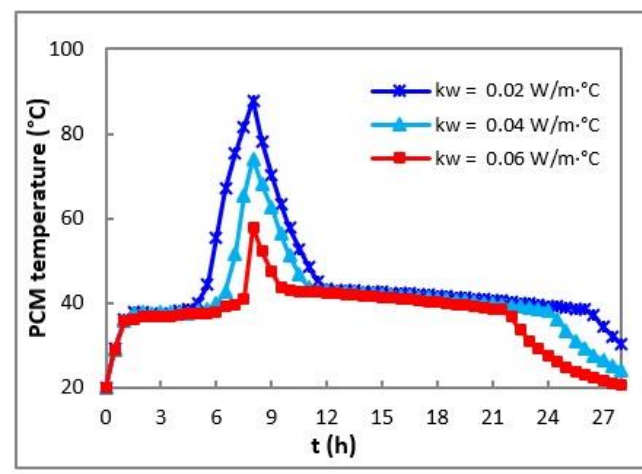

(a)

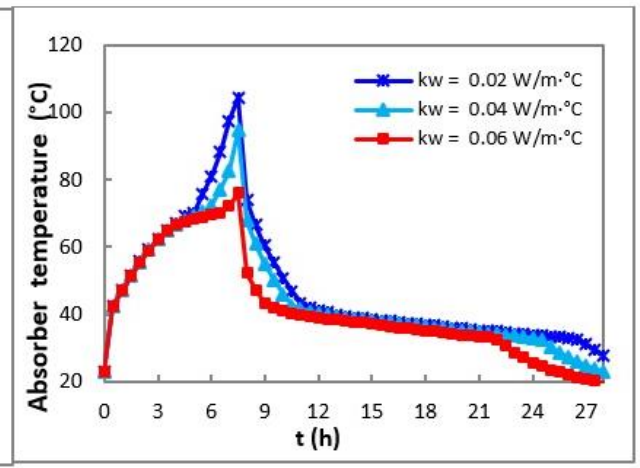

(b)

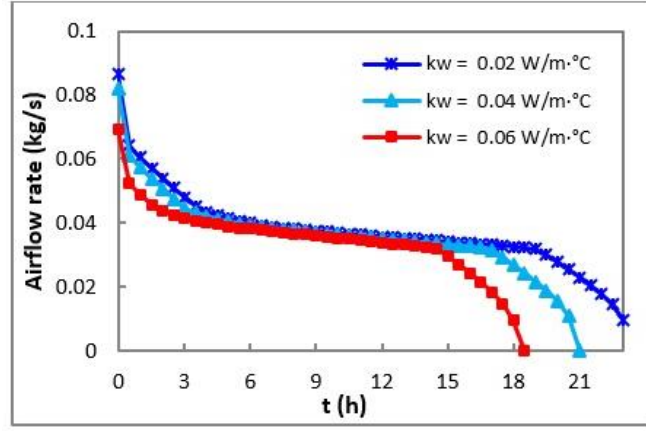

(c)

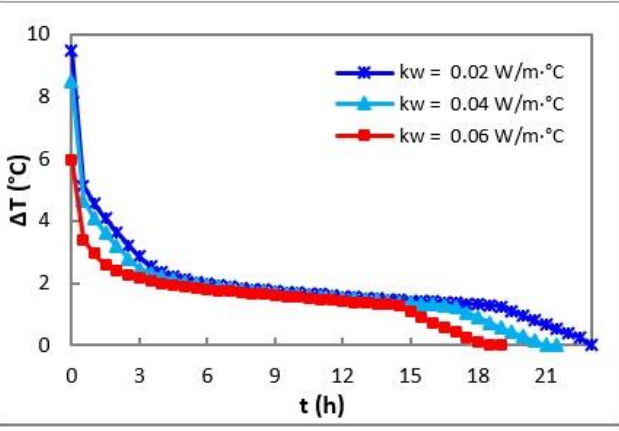

(d)

Fig.10. Effect of thermal conductivity of the insulation material on: (a) melting and freezing time; (b) absorber surface temperature; (c) airflow rate; (d) air temperature difference $\Delta \mathrm{T}$ 


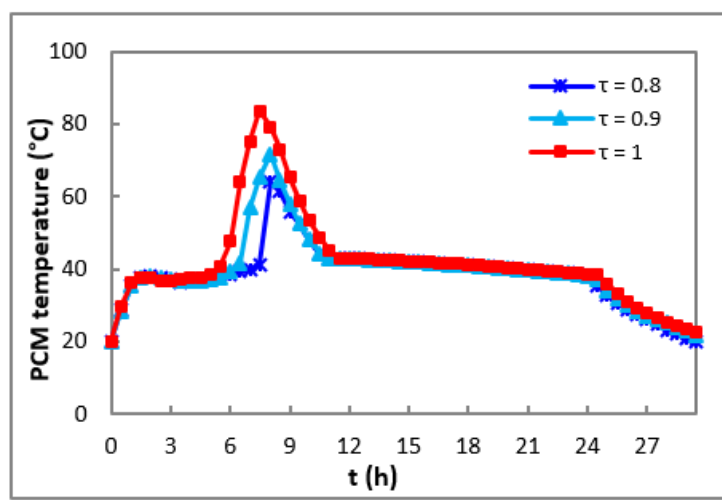

(a)

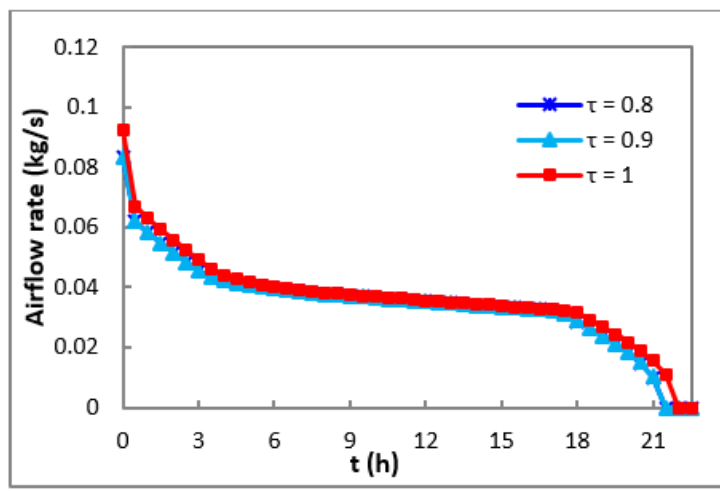

(c)

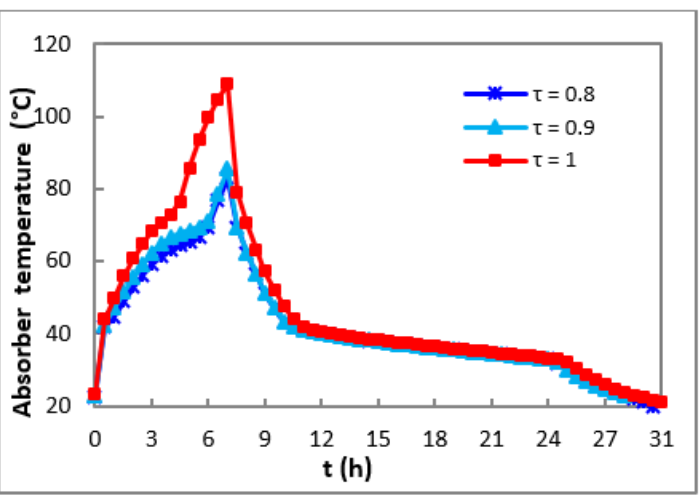

(b)

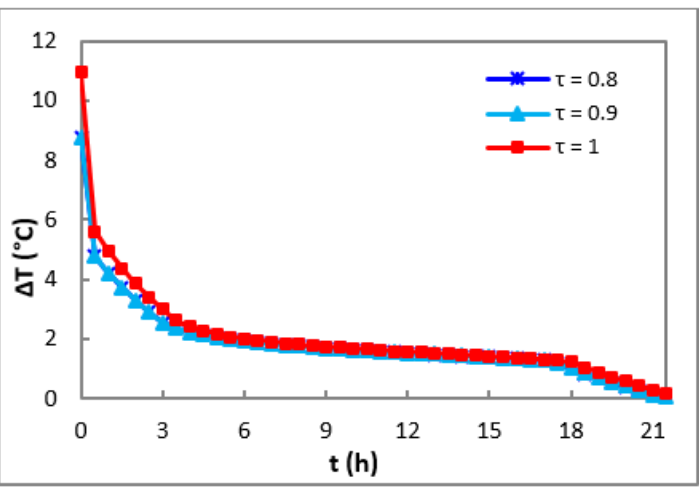

(d)

Fig.11. Effect of transmissivity of the glass cover on: (a) melting and freezing times; (b) absorber surface temperature; (c) airflow rate; (d) air temperature difference $\Delta \mathrm{T}$ 


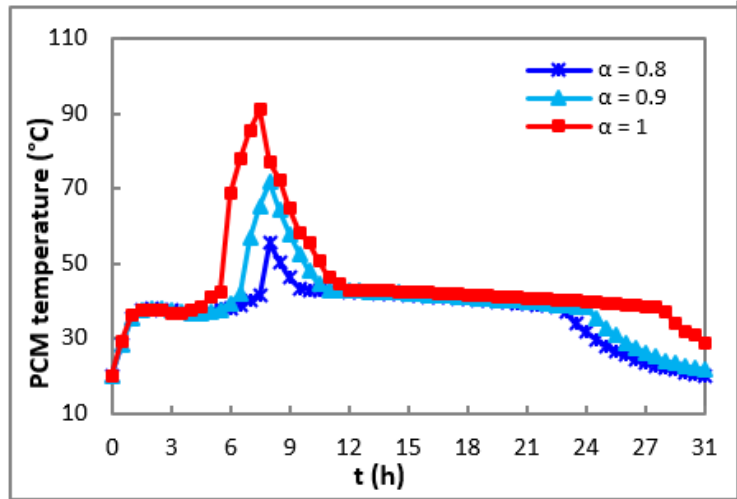

(a)

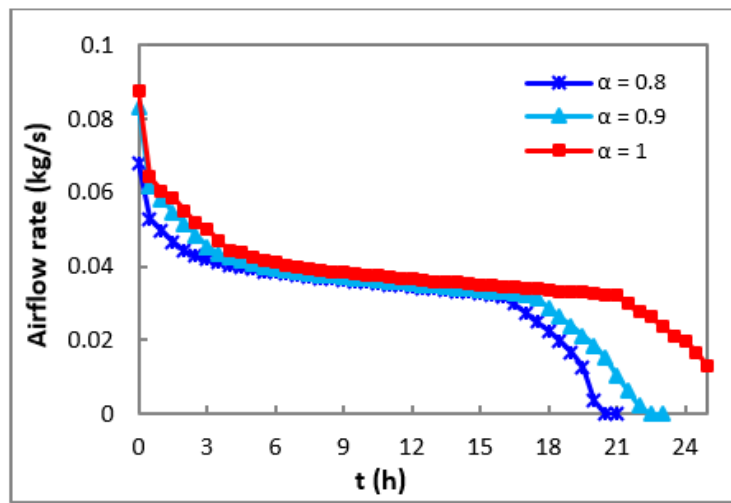

(c)

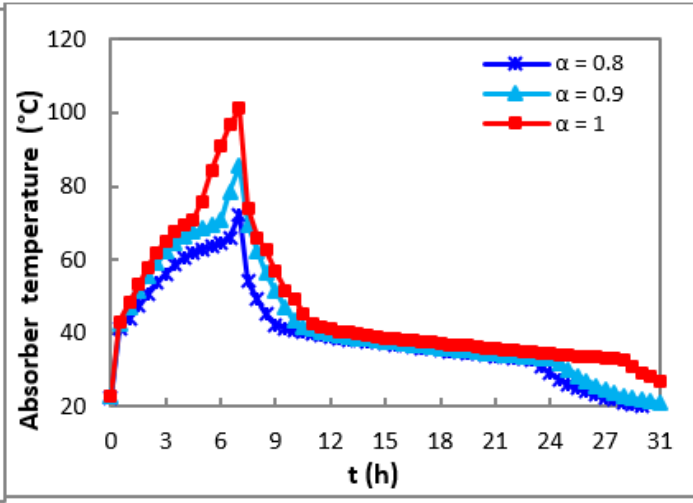

(b)

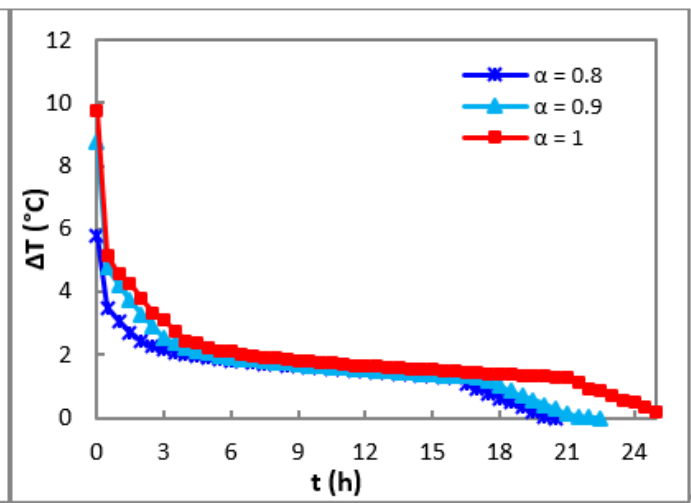

(d)

Fig.12. Effect of absorptivity of the absorber surface on: (a) melting and freezing times; (b) absorber surface temperature; (c) airflow rate; (d) air temperature difference $\Delta \mathrm{T}$ 